\title{
Development of Electro-chemical Battery Model for Plug-and-Play Eco-system Library
}

IES Simulation Ecosystem Control System Development

Nuclear Science and Engineering Division 


\section{About Argonne National Laboratory}

Argonne is a U.S. Department of Energy laboratory managed by UChicago Argonne, LLC under contract DE-AC0206CH11357. The Laboratory's main facility is outside Chicago, at 9700 South Cass Avenue, Argonne, Illinois 60439. For information about Argonne

and its pioneering science and technology programs, see www.anl.gov.

\section{DOCUMENT AVAILABILITY}

Online Access: U.S. Department of Energy (DOE) reports produced after 1991 and a growing number of pre-1991 documents are available free at OSTI.GOV (http://www.osti.gov/), a service of the US Dept. of Energy's Office of Scientific and Technical Information.

Reports not in digital format may be purchased by the public from the

National Technical Information Service (NTIS):

U.S. Department of Commerce

National Technical Information Service

5301 Shawnee Rd

Alexandria, VA 22312

www.ntis.gov

Phone: (800) 553-NTIS (6847) or (703) 605-6000

Fax: (703) 605-6900

Email: orders@ntis.gov

Reports not in digital format are available to DOE and DOE contractors from the Office of Scientific and Technical Information (OSTI):

U.S. Department of Energy

Office of Scientific and Technical Information

P.O. Box 62

Oak Ridge, TN 37831-0062

www.osti.gov

Phone: (865) 576-8401

Fax: (865) 576-5728

Email: reports@osti.gov

\section{Disclaimer}

This report was prepared as an account of work sponsored by an agency of the United States Government. Neither the United States Government nor any agency thereof, nor UChicago Argonne, LLC, nor any of their employees or officers, makes any warranty, express or implied, or assumes any legal liability or responsibility for the accuracy, completeness, or usefulness of any information, apparatus, product, or process disclosed, or represents that its use would not infringe privately owned rights. Reference herein to any specific commercial product, process, or service by trade name, trademark, manufacturer, or otherwise, does not necessarily constitute or imply its endorsement, recommendation, or favoring by the United States Government or any agency thereof. The views and opinions of document authors expressed herein do not necessarily state or reflect those of the United States Government or any agency thereof, Argonne National Laboratory, or UChicago Argonne, LLC. 
ANL/NSE-21/26

\section{Development of Electro-chemical Battery Model for Plug-and- Play Eco-system Library}

IES Simulation Ecosystem Control System Development

prepared by

Haoyu Wang, Roberto Ponciroli, Richard B. Vilim

Nuclear Science and Engineering Division, Argonne National Laboratory

August 31, 2021 


\section{Table of Contents}

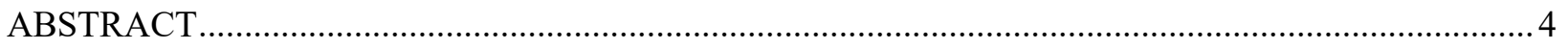

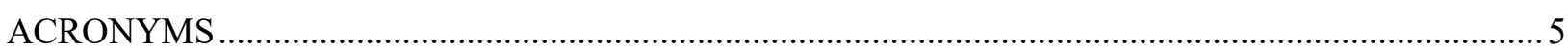

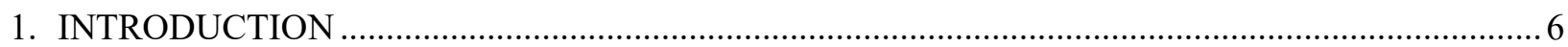

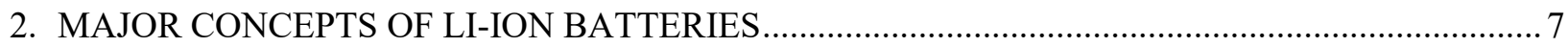

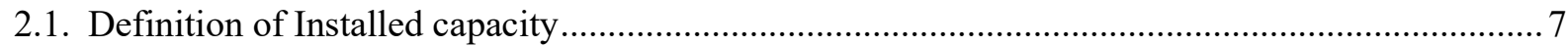

2.2. Battery system components, i.e., cells, modules, packs........................................................... 8

3. DEVELOPMENT OF THE “LEVEL_2” BATTERY MODEL …......................................................

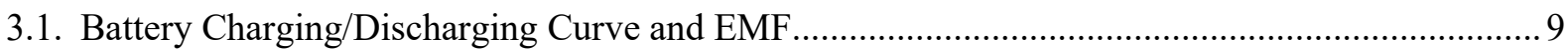

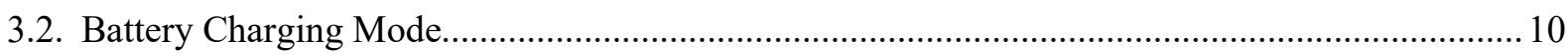

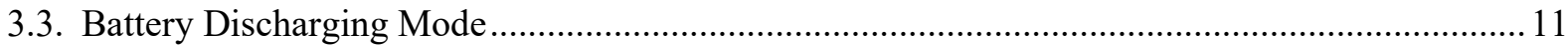

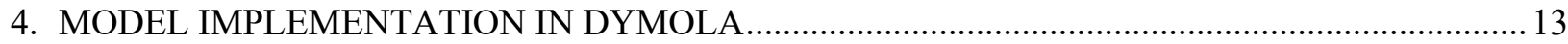

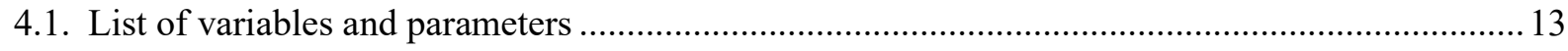

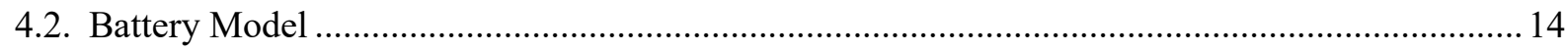

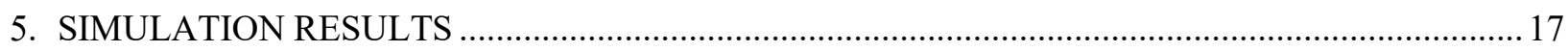

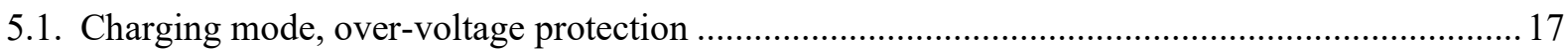

5.2. Charging mode, over-charge and over-current protection ........................................................ 18

5.3. Discharging mode, over-discharge and over-current protection.................................................. 19

5.4. Discharging mode, over-power protection............................................................................. 20

6. HERON MODELING OF DEGRADATION PHENOMENA AFFECTING ELECTRO-CHEMICAL

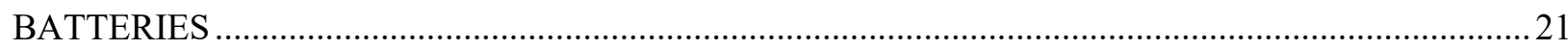

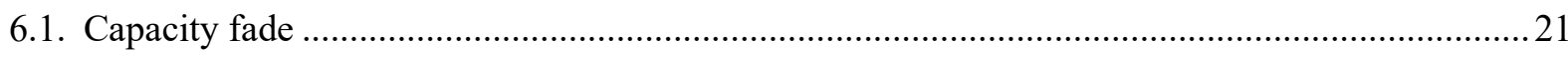

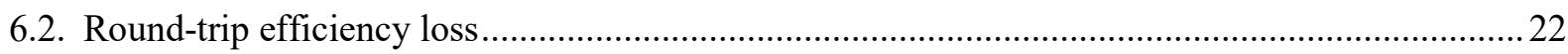

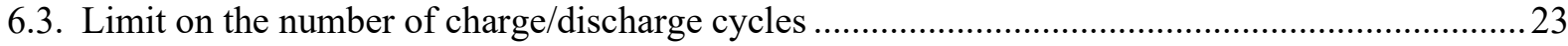

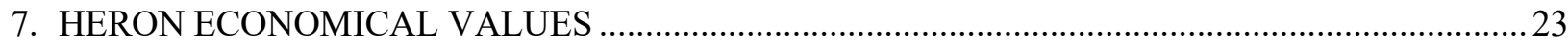

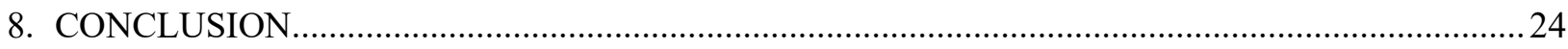

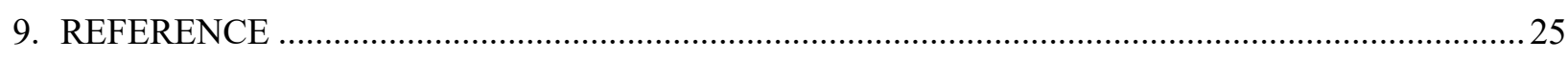

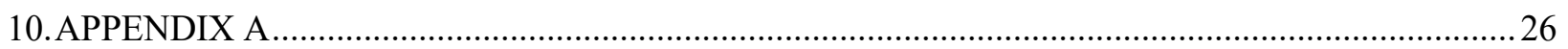




\section{List of Figures}

Figure 2-1. Representation of the installed capacity of a battery.

Figure 2-2. Scheme of the cell, module and pack in the battery model and the connection with the grid.... 8

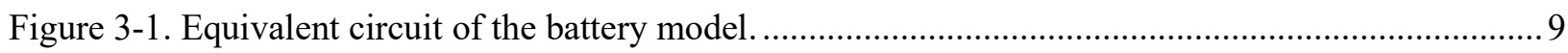

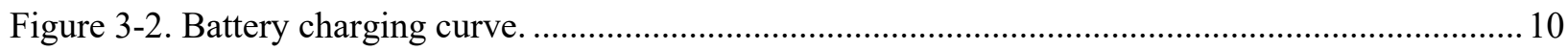

Figure 3-3. Schematic view of the battery equivalent in "charging mode"........................................... 11

Figure 3-4. Schematic view of the battery equivalent in "discharging mode". ....................................... 13

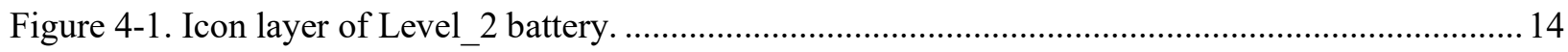

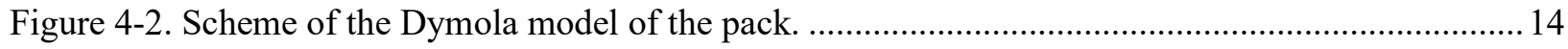

Figure 4-3. Diagram layer of battery reference model....................................................................... 15

Figure 5-1. Power, EMF and SOC traces for over-voltage and over-power protection demonstration...... 17

Figure 5-2. Power, current and SOC trajectories for over-charge and over-current protection

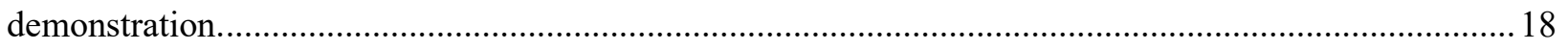

Figure 5-3. Power, EMF and current traces for over-charge and over-current protection demonstration.. 19

Figure 5-4. Power, EMF and current traces for over-power protection demonstration............................ 20 


\section{List of Tables}

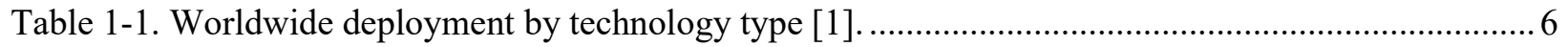

Table 3-1. Battery parameters and major process variables. ............................................................... 10

Table 4-1. Adopted design parameters for the Dymola battery model................................................. 13

Table 4-2. Variables in adopted battery model. ................................................................................ 14

Table 7-1. Summary of costs and parameters for a reference Li-ion battery unit..................................23 


\section{ABSTRACT}

Energy storage components are fundamental to the concept of an Integrated Energy System (IES). They serve to store surplus energy during low-demand periods for later release when other IES components (i.e., Secondary Energy Source, Balance of Plant, etc.) would otherwise have to operate flexibly. This provision for storage avoids high-amplitude power ramps in these components thereby limiting thermal and mechanical stresses to their internals and providing for extended service life.

This report describes a dynamic model that has been developed for an electrochemical battery. The lithium-ion (Li-ion) cell was selected as representative technology. The battery model was developed in the Dymola simulation environment and meets the requirements of the ecosystem plug-and-play library. The model accurately describes the electric dynamic response of a Li-ion battery for an imposed charging/discharging power profile. The corresponding physical limitations related to over-power scenarios, and the impact of the residual state of charge are accounted for in the model.

A literature review of the major degradation processes affecting Li-ion batteries was performed. Given the purposes of the CTD-IES project, the progressive fade of the installed capacity, the reduction of the round-trip efficiency, and the limits on the number of charging/discharging cycles are aspects that need to be taken into account in techno-economic analyses. The modeling of these degradation phenomena becomes crucial when predictions over long time horizons (capacity expansion) are made. For each one of these phenomena, a brief description is given, and some figures to be implemented in the HERON optimization algorithm are presented. 


\section{ACRONYMS}

$\begin{array}{ll}\text { Ah } & \text { Ampere-hour } \\ \text { BMS } & \text { Battery Management System } \\ \text { BOL } & \text { Beginning Of Life } \\ \text { CAES } & \text { Compressed Air Energy Storage } \\ \text { CAPEX } & \text { Capital expenditure } \\ \text { DoD } & \text { Depth of Discharge } \\ \text { EFC } & \text { Equivalent Full Cycle } \\ \text { EMF } & \text { Electro-Motive Force } \\ \text { IES } & \text { Integrated Energy System } \\ \text { HERON } & \text { Holistic Energy Resource Optimization Network } \\ \text { Li } & \text { Lithium } \\ \text { N-R HES } & \text { Nuclear-Renewable Hybrid Energy System } \\ \text { O\&M } & \text { Operation and Maintenance } \\ \text { PSH } & \text { Pumped Storage Hydropower } \\ \text { RTE } & \text { Round Trip Efficiency } \\ \text { SEI } & \text { Solid Electrolyte Interface } \\ \text { SOC } & \text { State of Charge } \\ \text { SOH } & \text { State of Health }\end{array}$




\section{INTRODUCTION}

Energy storage components are fundamental to the concept of an Integrated Energy System (IES). They serve to store surplus energy during low-demand periods for later release when other IES components (i.e., Secondary Energy Source, Balance of Plant, etc.) would otherwise have to operate flexibly. This provision for storage avoids high-amplitude power ramps in these components thereby limiting thermal and mechanical stresses to their internals and providing for extended service life.

As of 2018, nearly $173 \mathrm{GW}$ of energy storage had been deployed across the world. Information was gathered from the DOE Storage Database and compiled by technology type [1]. Pumped storage hydropower (PSH), being primarily a grid-scale storage technology, represents the $98 \%$ of worldwide energy storage deployed (nearly 170,000 MW). Within the remaining $2 \%$ of capacity deployed internationally by all other technologies, Lithium-ion (Li-ion) storage composes roughly half of the energy storage (Table 1-1). To this aim, Li-ion batteries were selected as representative technology of electrochemical energy storage systems. The name originates from the transfer of lithium ions between the electrodes (lithiated metal oxides as the cathode, graphite as the anode), both when energy is injected for storage purposes and when it is extracted. Unlike other batteries with electrodes that change by charging and discharging, Li-ion batteries offer better efficiency because the ion movements leave electrode structures intact. For short-duration storage applications (from 30 minutes to 3 hours), lithium batteries are currently the most cost-effective solution by representing $\sim 90 \%$ of the market. The typical power ranges from $1 \mathrm{~kW}$ to $100 \mathrm{MW}$, and typical energy-storing capabilities might get to $200 \mathrm{MWh}$ [1]. Besides, they have the best energy density $(250 \sim 530 \mathrm{Wh} / \mathrm{L})$ compared to the other technologies. At the same time, Liion might not be the most cost-effective choice for longer durations, particularly when considering lifetime costs.

Table 1-1. Worldwide deployment by technology type [1].

\begin{tabular}{lc}
\hline \multicolumn{1}{c}{ Technology } & MW deployed \\
\hline Sodium sulfur & 189 \\
Lithium-ion & 1,629 \\
Lead acid & 75 \\
Sodium metal halide & 19 \\
Flows battery & 72 \\
PSH & 169,557 \\
CAES & 407 \\
Flywheels & 931 \\
Electrochemical capacitor & 49 \\
\hline Total & 172,928 \\
\hline
\end{tabular}

In this report, the dynamic model of a Li-ion battery complying with the requirements of the ecosystem plug-and-play library was realized in Dymola simulation environment. First, the main concepts of electrochemical batteries are resented. In Section 2.1, the concept of installed capacity is explored, and then the main components that constitute the ensemble we will refer to as "battery" (cell, module, pack) are introduced in Section 2.2. In Section 3, the adopted model to describe the electric dynamic response of a 
Li-ion battery ensuing from an imposed power profile (both charging and discharging phases) is presented. In Section 4 and Section 5, the implementation of the model in Dymola and the outcome of the conducted simulations is described.

Finally, a literature review about the major degradation processes affecting Li-ion batteries is provided (Section 6). The progressive reduction of the installed capacity and the round-trip efficiency, and the limits on the number of charging/discharging cycles are aspects that need to be taken into account in technoeconomic analyses. The modeling of these phenomena becomes crucial when predictions over long time horizons (capacity expansion) are made. For each one of these phenomena, a brief description is given, and some figures to be implemented in HERON optimization algorithm are reported in Section 7.

\section{MAJOR CONCEPTS OF LI-ION BATTERIES}

\subsection{Definition of Installed capacity}

The capacity of a battery corresponds to the quantity of the electric charge that can be accumulated during the charge, stored during the open circuit stay, and released during the discharge in a reversible manner. As shown in Figure 2-1, it is obtained by integration of the discharge current starting from a completely charged battery and terminating the discharge process at certain voltage threshold Error!

\section{Reference source not found.}
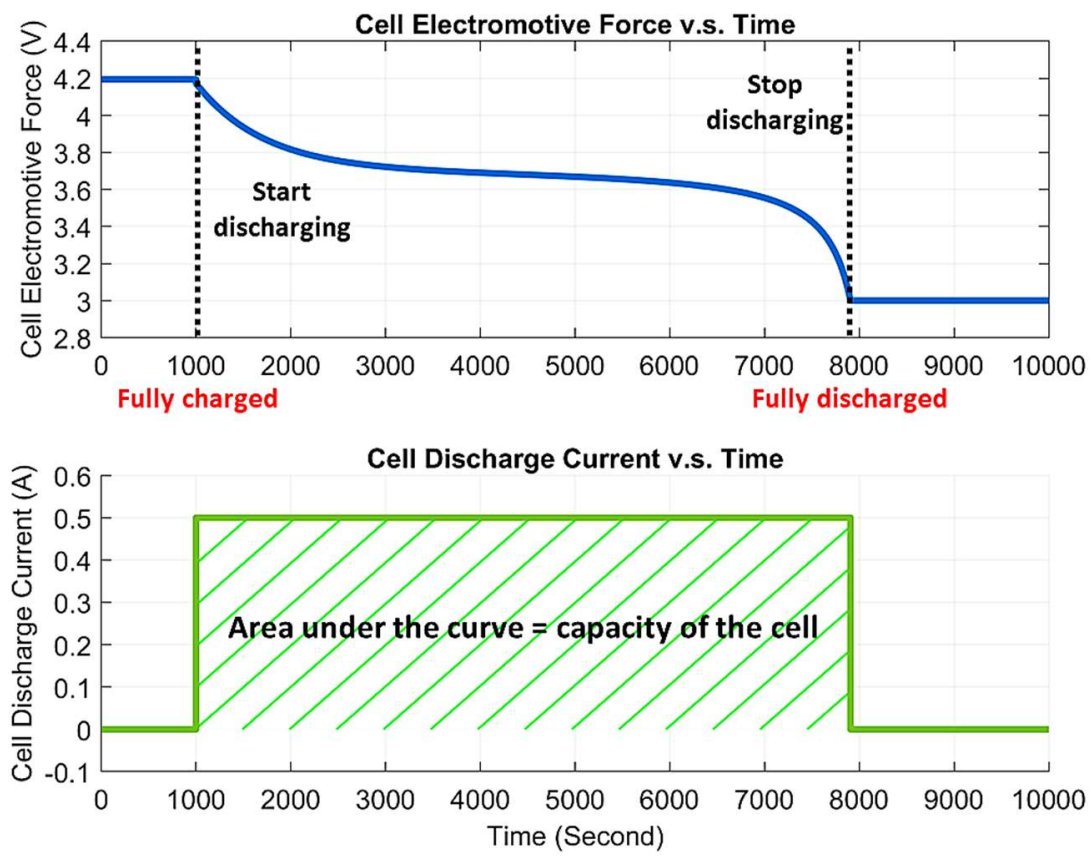

Figure 2-1. Representation of the installed capacity of a battery.

The installed capacity of a battery represents the maximum amount of energy that can be extracted from the battery under certain conditions. At the same time, the actual energy storage capabilities of the battery can vary significantly from the nominal capacity, as the battery capacity strongly depends on the age and history of the battery, the charging or discharging regimes of the battery and the temperature. The battery capacity is measured in either watt-hours $(\mathrm{Wh})$, kilowatt-hours $(\mathrm{kWh})$, or ampere-hours $(\mathrm{Ah})$. The most common measure of battery capacity is (Ah), i.e., the number of hours for which a battery can provide a 
current equal to the discharge rate at the nominal voltage. This unit is commonly used when working with battery systems as the battery voltage will vary throughout the charging or discharging cycle.

\subsection{Battery system components, i.e., cells, modules, packs}

Li-ion batteries are configurable into a variety of string sizes and battery racks to create a wide range of voltages, power ratings, or energy increments. This allows for application-specific designs that can range from a few kilowatts with a few minutes of storage, up to multi-megawatt solutions with hours of storage that may be used at a utility substation or a wind farm (Figure 2-2).

A "cell" consists of the electrochemical unit with the lowest voltage of the associated chemistry. It represents the smallest unit of a battery, comprised of four key components, i.e., cathode, anode, electrolyte and separator. A cell must possess high capacity per unit volume to show maximum performance in a restricted area inside a vehicle and the cell also needs to have much longer lifespan compared to batteries used in general mobile devices. Furthermore, cells must endure shocks transmitted during the drive and possess high reliability and stability to the extent of being able to withstand high and low temperatures.

When several cells are put into a frame to protect them better from external shocks such as heat or vibration, this is called a "module". A module consists of multiple cells connected in series and/or parallel, encased in a mechanical structure. When several modules are organized in series and parallel and they are coupled with a BMS (Battery Management System) and a cooling device, this is called a "pack". For applications in the electric grid, Li-ion battery-based energy storage systems are expected to last for a decade or even longer. A typical MWh system may contain as many as 100,000 cells assembled into packs [3].

Battery \& Storage System

System Coupling

Grid Integration

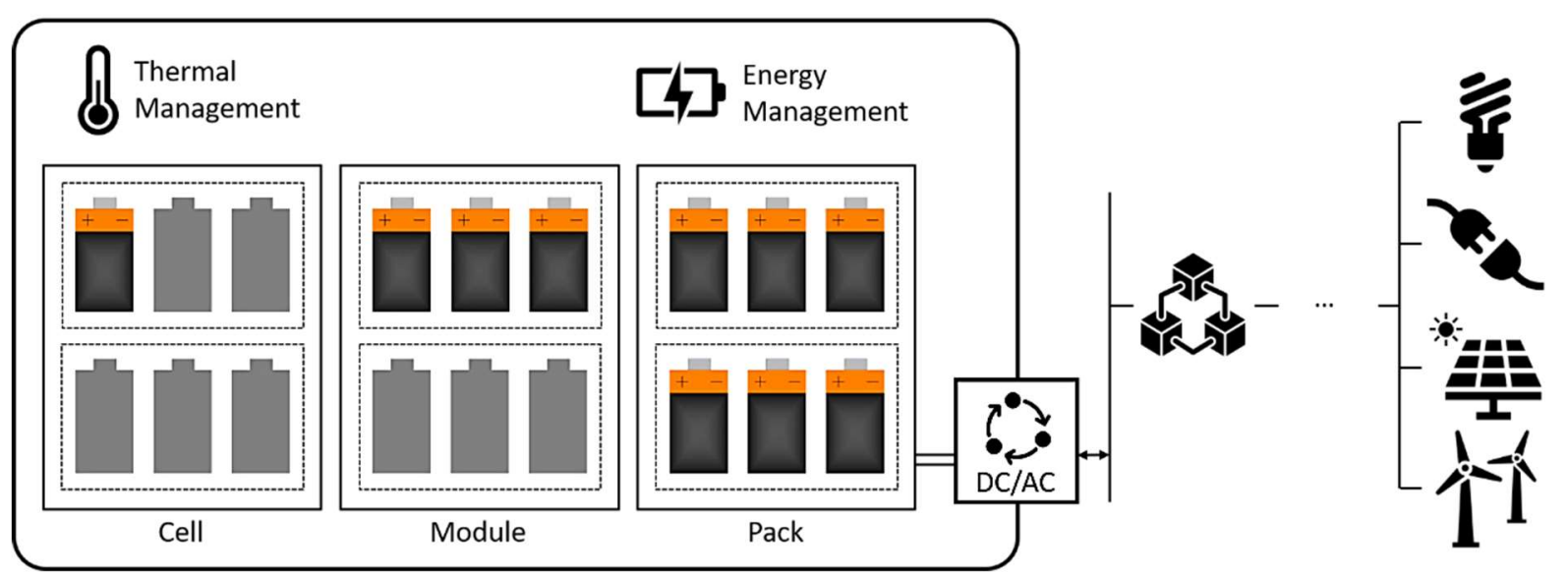

Figure 2-2. Scheme of the cell, module and pack in the battery model and the connection with the grid.

The BMS for a battery pack is used to monitor and control the voltage differences between cells and the temperature of individual cells within the pack. The battery management system ensures that the cells are not allowed to exceed the manufacturer's specified voltage and temperature for the battery system [4][5]. In [6], an example of how cells, modules and packs are assembled is provided. To obtain a $1 \mathrm{MWh}$ battery, an operating voltage of $760 \mathrm{~V}$ to $1053 \mathrm{~V}$ with a nominal operating voltage of $947 \mathrm{~V}$ and $1200 \mathrm{Ah}$ is considered. A single cell of the battery system is initially modeled with the voltage at $4.12 \mathrm{~V}$ and current at $60 \mathrm{~A}$. Once the single cell of $3.7 \mathrm{~V}$ is modeled, 256 such cells are stacked in series to obtain a voltage of 
$947 \mathrm{~V}$ and current of 60A. Modules are connected in parallel to increase the current to $1200 \mathrm{Ah}$ with 947 V.

\section{DEVELOPMENT OF THE "LEVEL_2" BATTERY MODEL}

Within the CTD-IES project, models for electrochemical batteries were first developed in [7]. In particular, descriptions characterized by different levels of complexity were proposed:

- "Level_0" battery model simply echoed the demanded charging or discharging power as output.

- "Level_1" battery model had the limited installed capacity feature implemented, i.e., the battery models stopped charging or discharging when the energy storing capabilities got saturated.

In both "Level_0" and "Level_1" models, the battery was described as a simple power source/sink, and no detailed electrical process variables were provided. Based on the set of equations describing the equivalent circuit, the model of Li-ion battery described in the next Sections ("Level_2") will ensure a more accurate representation of the battery electrical response during charging (Section 3.2) and discharging (Section 3.3).

\subsection{Battery Charging/Discharging Curve and EMF}

In Figure 3-1, the battery equivalent circuit is represented. Basically, it is constituted by a controlled voltage source and an internal resistance.

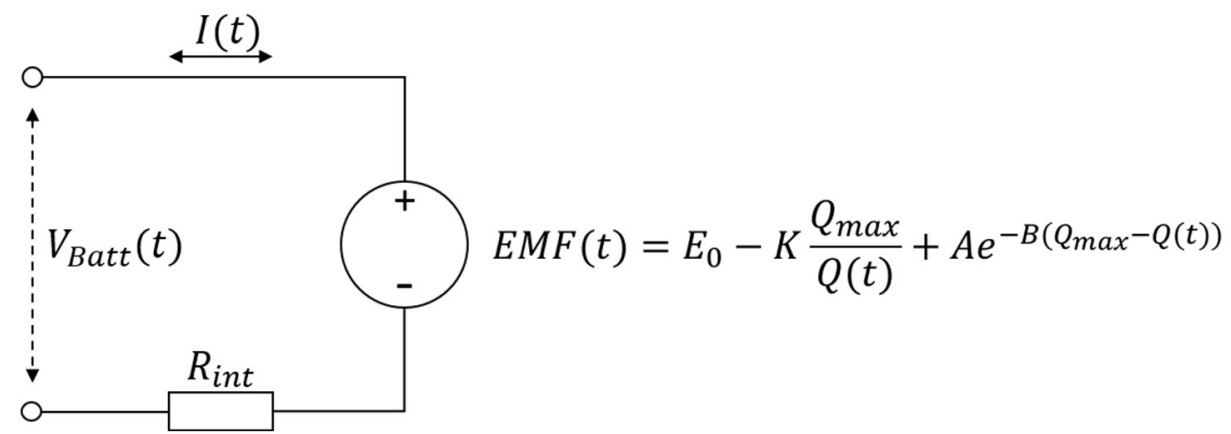

Figure 3-1. Equivalent circuit of the battery model.

The dynamic battery terminal voltage is described by the modified Shepherd model [8], which accounts for the current, state-of-charge (SOC), and other characteristics of the battery, and it can be used to describe both charging and discharging process (Eqs.(1)(2)(3)). The corresponding variables and parameters defined in Table 3-1.

$$
\begin{aligned}
& E M F(t)=E_{0}-K \frac{Q_{\max }}{Q(t)}+A e^{-B\left(Q_{\max }-Q(t)\right)} \\
& V_{\text {Batt }}(t)=E M F(t)-I(t) * R_{\text {int }} \\
& \frac{d Q(t)}{d t}+I(t)=0
\end{aligned}
$$

To indicate the percentage charge level of the battery, the SOC equation is considered (Eq. (4)). 


$$
\operatorname{SOC}(t)=\frac{Q(t)}{Q_{\max }}
$$

It is worth noting that the parameters in Eq. (1) may assume different values from charging mode to discharging mode, providing slightly different charging curve and discharging curve. The exponential and reciprocal term is valid for Li-ion battery, and they are critical in Shepherd model for representing the exponential voltage rise near the full capacity and the quick voltage drop near the capacity depletion, as shown in Figure 3-2.

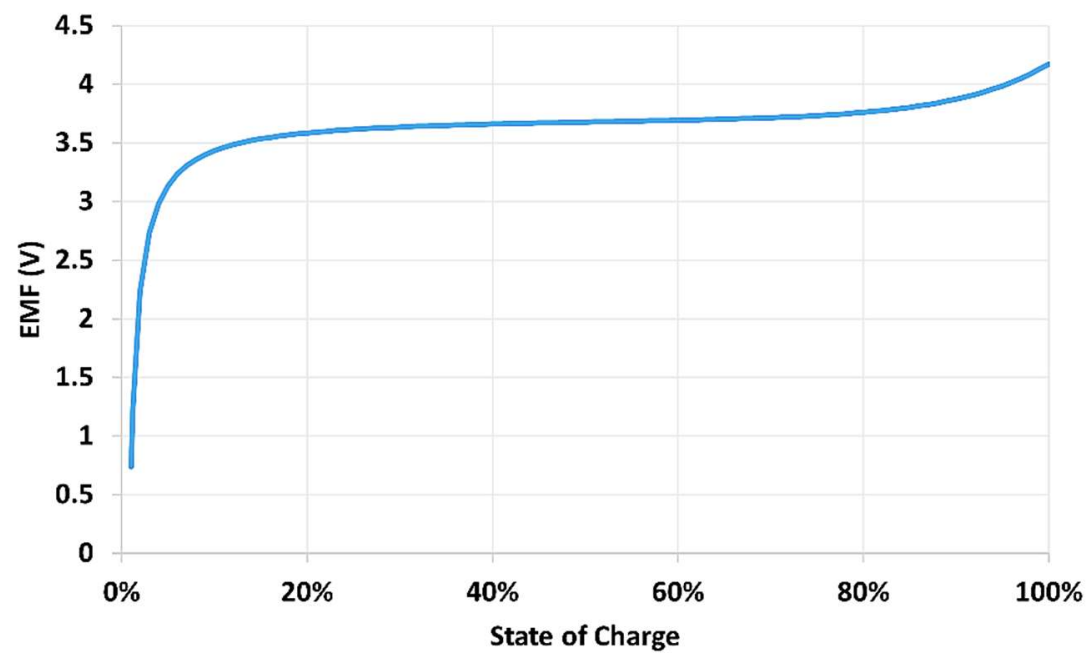

Figure 3-2. Battery charging curve.

Table 3-1. Battery parameters and major process variables.

\begin{tabular}{cl}
\hline Parameter/Variable & Definition \\
\hline$E_{0}$ & Battery constant voltage $(\mathrm{V})$ \\
$K$ & Polarization constant $(\mathrm{V})$ \\
$Q_{\max }$ & Maximum allowed charge (Ah) \\
$A$ & Exponential zone amplitude $(\mathrm{V})$ \\
$B$ & Charge constant inverse $\left(\mathrm{A}^{-1} \mathrm{~h}^{-1}\right)$ \\
$R_{\text {int }}$ & Internal resistance $($ ohm $)$ \\
$E M F(t)$ & Battery electromotive force $(\mathrm{V})$ \\
$V_{\text {batt }}(t)$ & Battery terminal voltage $(\mathrm{V})$ \\
$Q(t)$ & Residual battery charge $(\mathrm{Ah})$ \\
$I(t)$ & Battery current (A), Discharge $(+) /$ Charge $(-)$ \\
\hline
\end{tabular}

\subsection{Battery Charging Mode}

When operated in "charging mode", the battery is meant to receive the surplus power produced by the other IES unit components. This scenario is represented by a dedicated power-imposed boundary condition $\left(P_{\text {set }}(t)\right)$, and an external voltage source $\left(V_{C}\right)$ is connected to the battery equivalent circuit (Figure 3-3). To 
better represent the electrical behavior of the real battery, a series of constraints are identified, and the charging voltage from the external voltage source needs to be adjusted to its maximum possible value to meet the demanded power without violating these constraints. Firstly, the residual charge on the battery $(Q(t))$ cannot exceed the maximum allowed charge, which provides the feature of over-charge protection (Eq. (5)).

$$
Q(t) \leq Q_{\max }, \text { or } \operatorname{SOC}(t) \leq 1.0
$$

Secondly, the external charging voltage $\left(V_{C}(t)\right)$ cannot exceed the maximum allowed charging voltage, which provides the feature of over-voltage protection (Eq. (6)).

$$
V_{C}(t) \leq V_{C, \operatorname{Max}}
$$

Thirdly, the battery current $I(t)$ cannot exceed the maximum allowed charging current, which provides the feature of over-current protection (Eq. (7)).

$$
|I(t)|=\left|\frac{E M F(t)-V_{C}}{R_{\text {int }}}\right|<I_{C, \operatorname{Max}}
$$

Finally, the absolute value of battery terminal power cannot exceed the demanded power, which provides the feature of over-power protection (Eq. (8)).

$$
\left|P_{\text {Batt }}(t)\right|=V_{C}(t) *|I(t)| \leq\left|P_{\text {set }}(t)\right|
$$

The model aims at finding the maximum value of external charging voltage, without violating any of the above-mentioned constraints.

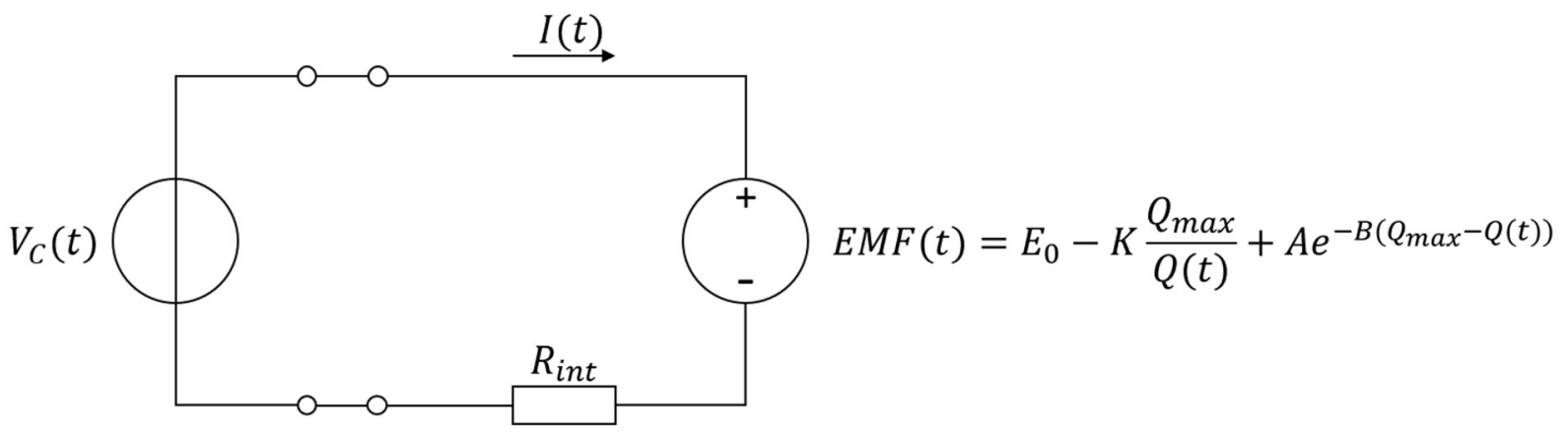

Figure 3-3. Schematic view of the battery equivalent in "charging mode".

\subsection{Battery Discharging Mode}

When operated in "discharging mode", the battery is modeled as connected to an external load (Figure 3-4). A series of constraints are identified, and the battery current needs to be adjusted to its maximum possible value to meet the demanded power without violating any of them. Firstly, the battery electromotive force $(E M F(t))$ cannot be lower than the cut-off voltage $\left(E M F_{M i n}\right)$, which provides the feature of overdischarge protection (Eq.(9)). 


$$
\operatorname{EMF}(t) \geq E M F_{\text {Min }}
$$

As for the constrains on battery current and output power, some calculations need to be done beforehand. For the system depicted in Figure 3-4, the power delivered by the battery can be calculated as:

$$
P_{\text {Batt }}(t)=V_{\text {Batt }}(t) * I(t)
$$

By substituting the expression of $V_{B a t t}(t)$ reported in Eq.(2),

$$
P_{\text {Batt }}(t)=\left(E M F(t)-I(t) * R_{\text {int }}\right) * I(t)
$$

After solving for the maximum value in Eq. (11), one can find the maximum deliverable power from the battery can be achieved at a battery current of $I(t)=\frac{E M F(t)}{2 \times R_{\text {int }}}$ :

$$
P_{\text {Batt }}(t) \leq P_{\text {Batt }}\left(I(t)=\frac{E M F(t)}{2 * R_{\text {int }}}\right)=\frac{E M F(t)^{2}}{4 * R_{\text {int }}}
$$

Due to the nature of quadratic function in Eq.(12), any value of output power below the maximum deliverable power $\frac{E M F(t)^{2}}{4 * R_{i n t}}$ can be achieved by two different battery current values $I_{1}(t)$ and $I_{2}(t)$, which are symmetric about the value $I(t)=\frac{E M F(t)}{2 * R_{\text {int }}}$. To avoid excessive heat dissipation on the internal resistance, the battery current $I(t)$ is limited to not exceeding either the symmetric axis value of $\frac{E M F(t)}{2 * R_{i n t}}$ or the maximum allowed discharging current $I_{D, \text { Max }}$, which provides the feature of over-current protection (Eq. (13)).

$$
I \leq \min \left(I_{D, \operatorname{Max}}, \frac{E M F(t)}{2 * R_{\text {int }}}\right)
$$

Finally, the output power $\left(P_{\text {Batt }}(t)\right)$ cannot exceed either the demanded power $P_{\text {set }}(t)$ or the maximum deliverable power $\frac{E M F(t)^{2}}{4 * R_{\text {int }}}$ (Eq. (14)).

$$
P_{\text {Batt }}(t) \leq \min \left(P_{\text {set }}(t), \frac{E M F(t)^{2}}{4 * R_{\text {int }}}\right)
$$

Similar to the charging mode, the model aims at finding the maximum value of battery current, without violating any of the above-mentioned constraints. 


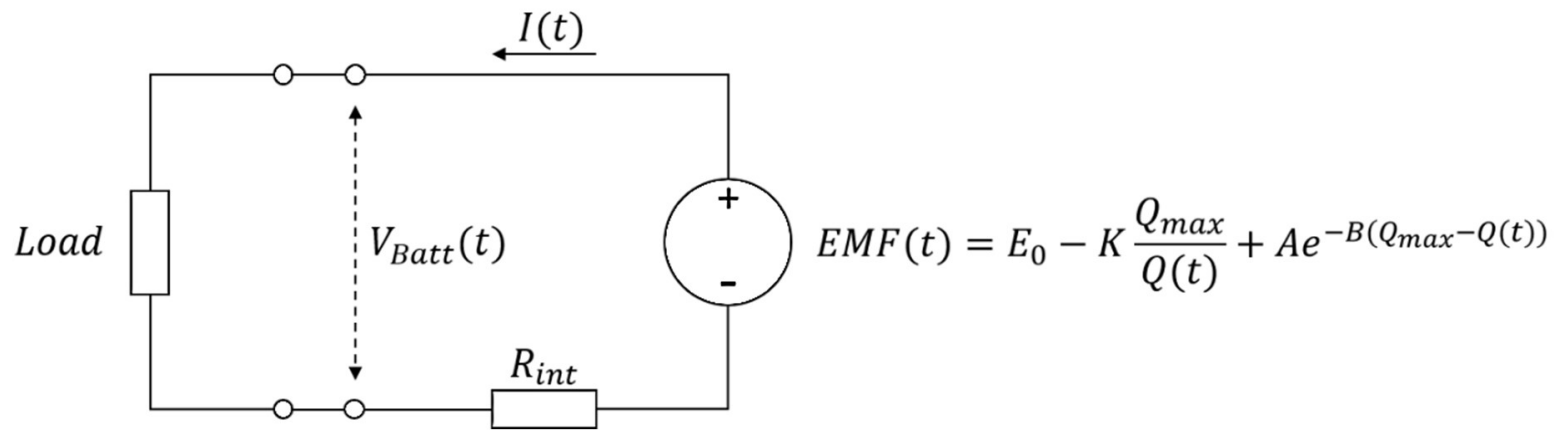

Figure 3-4. Schematic view of the battery equivalent in "discharging mode".

\section{MODEL IMPLEMENTATION IN DYMOLA}

In this Section, the details of the development of a Modelica model [9][10], based on the equations reported in Sections 3.1, 3.2 and 3.3, and the implementation in Dymola environment [11][12] are presented. The corresponding code is provided in Appendix A (Section 10).

\subsection{List of variables and parameters}

In Table 4-1, the battery design parameters and values discussed in Section 3 are listed. Most of the data are referred to a $3.7 \mathrm{~V}, 1000 \mathrm{mAh} \mathrm{Li-ion} \mathrm{battery} \mathrm{[8].} \mathrm{Other} \mathrm{values} \mathrm{were} \mathrm{taken} \mathrm{from} \mathrm{the} \mathrm{data} \mathrm{sheet} \mathrm{of} \mathrm{a}$ commercially available battery [13]. Note that the charging curve and discharging curve are independently defined by the parameter set $\left[E_{0, C}, K_{C}, A_{C}, B_{C}\right]$ and $\left[E_{0, D}, K_{D}, A_{D}, B_{D}\right]$. The asymmetric charging and discharging curves can better approach the battery performance in real-world environment.

Table 4-1. Adopted design parameters for the Dymola battery model.

\begin{tabular}{clc}
\hline Parameter & \multicolumn{1}{c}{ Definition } & Value \\
\hline$Q_{\text {max }}$ & Maximum allowed charge, (Ah) & 1.0 \\
$V_{C, \text { max }}$ & Maximum allowed charging voltage, $(\mathrm{V})$ & $4.2^{*}$ \\
$E M F_{\min }$ & Battery discharge cut-off voltage, $(\mathrm{V})$ & 3.0 \\
$I_{C, \text { max }}$ & Maximum allowed charging current, (A) & 1.0 \\
$I_{D, \text { max }}$ & Maximum allowed discharging current, (A) & $1.0^{*}$ \\
$R_{i n t}$ & Internal resistance, $(\Omega)$ & 0.09 \\
$E_{0, C}$ & Charging curve - Battery constant voltage, $(\mathrm{V})$ & 3.7348 \\
$K_{C}$ & Charging curve - Polarization constant, $(\mathrm{V})$ & 0.00876 \\
$A_{C}$ & Charging curve - Exponential zone amplitude, $(\mathrm{V})$ & 0.468 \\
$B_{C}$ & Charging curve - Charge constant inverse, $\left(\mathrm{A}^{-1} \mathrm{~h}^{-1}\right)$ & 3.5294 \\
$E_{0, D}$ & Discharging curve - Battery constant voltage, $(\mathrm{V})$ & 3.7348 \\
$K_{D}$ & Discharging curve - Polarization constant, $(\mathrm{V})$ & 0.03 \\
$A_{D}$ & Discharging curve - Exponential zone amplitude, $(\mathrm{V})$ & 0.468 \\
$B_{D}$ & Discharging curve - Charge constant inverse, $\left(\mathrm{A}^{-1} \mathrm{~h}^{-1}\right)$ & 10.0 \\
\hline
\end{tabular}


The variables describing the battery electrical response are listed in Table 4-2. The demanded charging/discharging power $\left(P_{\text {set }}(t)\right)$ is the only input variable to the simulation, and the charging voltage and battery current $\left(V_{C}(t)\right.$ and $I(t)$, respectively) will be solved by respecting all the constraints.

Table 4-2. Variables in adopted battery model.

\begin{tabular}{cll}
\hline Variable & \multicolumn{1}{c}{ Definition } & \multicolumn{1}{c}{ Note } \\
\hline$Q(t)$ & Residual battery charge, $(\mathrm{Ah})$ & Defined in Eq.(3) \\
$E M F(t)$ & Battery electromotive force, $(\mathrm{V})$ & Defined in Eq.(1) \\
$V_{\text {batt }}(t)$ & Battery terminal voltage, $(\mathrm{V})$ & Defined in Eq.(2) \\
$V_{C}(t)$ & External charging voltage, $(\mathrm{V})$ & To be solved \\
$I(t)$ & Battery charging $(-) /$ discharging $(+)$ current, $(\mathrm{A})$ & To be solved \\
$P_{\text {set }}(t)$ & Demanded charging $(-) /$ discharging $(+)$ power, $(\mathrm{W})$ & Problem Input \\
$P_{\text {batt }}(t)$ & Power delivered by the battery, $(\mathrm{W})$ & Defined in Eq.(9) \\
$S O C(t)$ & State of charge, $(-)$ & Defined in Eq.(4) \\
\hline
\end{tabular}

\subsection{Battery Model}

In Figure 4-1, the Dymola Icon layer of the "Level_2" battery model is shown. The blue triangle in the left-hand side of the figure represents the input port for the demanded power. The annular circle in the righthand side represents a connector. The battery operational mode is determined by the sign of demanded power, i.e., a negative power corresponds to charging and a positive power corresponds to discharging.

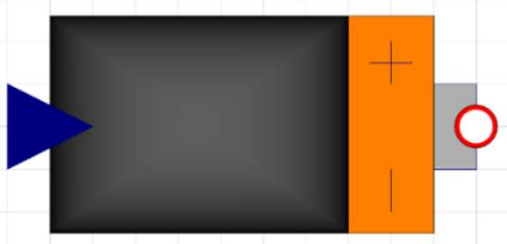

Figure 4-1. Icon layer of Level_2 battery.

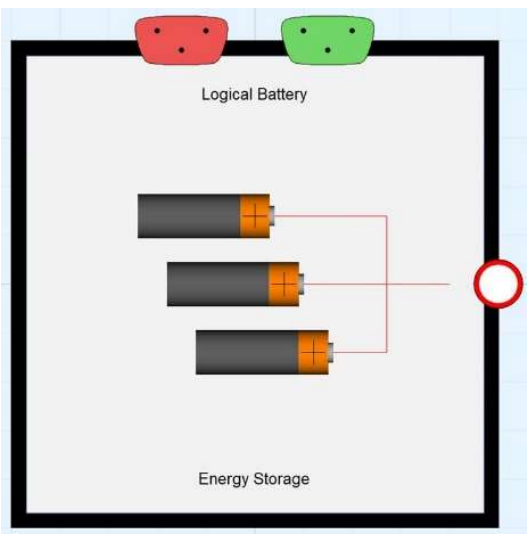

Figure 4-2. Scheme of the Dymola model of the pack. 


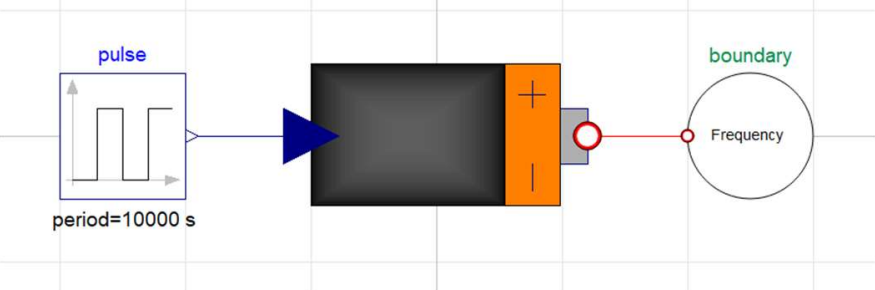

Figure 4-3. Diagram layer of battery reference model.

To meet N-R HES Modelica coding standard requirements [14], the model needs to be tested for all branches in the if-then-else constructs. The Diagram layer of the Battery-discharge example is shown in Figure 4-2. The squared source blocks in the left-hand side of the figure represents the input variable, i.e., the demanded charging/discharging power. The icon at the center represents the battery model (detailed view in Figure 4-3), and the circle in the right-hand side of the figure represents an electrical energy sink. During simulations, the battery will respond to the demanded charging/discharging power according to its residual charges and the constraints in voltage, current and power, and receive/output electrical power from/to the electrical energy sink. The main algorithm and equations governing the response of this battery model can be explained by the following pseudocode.

\section{Charging Mode:}

- Battery electromotive force is defined by Eq. (15):

$$
E M F(t)=E_{0, C}-K_{C} \frac{Q_{\max }}{Q(t)}+A_{C} e^{-B_{C}\left(Q_{\max }-Q(t)\right)}
$$

- If residual charge exceeds the maximum allowed charge $\left(Q(t)>Q_{\max }\right)$, or the battery electromotive force exceeds the maximum allowed charging voltage $\left(E M F(t)>V_{C, \text { Max }}\right)$, do not charge the battery:

$$
\begin{aligned}
& V_{C}(t)=0 \\
& I(t)=0
\end{aligned}
$$

- If battery charging current is within its upper limit when charged at maximum allowed charging voltage $\left(\frac{V_{C, M a x}-E M F(t)}{R_{\text {int }}}<I_{C, \operatorname{Max}}\right)$ :

- If demanded power is within the power when charged at maximum allowed charging voltage $\left(\left|P_{\text {set }}(t)\right|<V_{C, \text { Max }} \cdot \frac{V_{C, \text { Max }}-E M F(t)}{R_{\text {int }}}\right)$, solve for the external charging voltage (Eq.(17)). The result is reported in Eq.(18).

$$
\begin{aligned}
& V_{C}(t) \cdot \frac{V_{C}(t)-E M F(t)}{R_{\text {int }}}=\left|P_{\text {set }}(t)\right| \\
& V_{C}(t)=\frac{E M F(t)+\sqrt{E M F(t)^{2}+4 \cdot R_{\text {int }} \cdot\left|P_{\text {Set }}(t)\right|}}{2} \\
& I(t)=\frac{E M F(t)-\sqrt{E M F(t)^{2}+4 \cdot R_{\text {int }} \cdot\left|P_{\text {Set }}(t)\right|}}{2 \cdot R_{\text {int }}}
\end{aligned}
$$


$\circ$ If demanded power exceeds the power when charged at maximum allowed charging voltage $\left(\left|P_{\text {set }}(t)\right| \geq V_{C, \operatorname{Max}} \cdot \frac{V_{C, M a x}-E M F(t)}{R_{\text {int }}}\right)$, charge the battery at the maximum allowed charging voltage, as shown in Eq.(19).

$$
\begin{aligned}
& V_{C}(t)=V_{C, M a x} \\
& I(t)=\frac{E M F(t)-V_{C, M a x}}{R_{\text {int }}}
\end{aligned}
$$

- If battery charging current exceeds its upper limit when charged at maximum allowed charging voltage $\left(\frac{V_{C, M a x}-E M F(t)}{R_{\text {int }}} \geq I_{C, \operatorname{Max}}\right)$ :

$\circ$ If demanded power is within the power when charged at maximum allowed charging current $\left(\left|P_{\text {set }}(t)\right|<I_{C, \text { Max }} \cdot\left(E M F(t)+I_{C, \text { Max }} \cdot R_{\text {int }}\right)\right.$, solve for the charging current (Eq. (20)). This equation is equivalent to Eq. (19), so the result is the same to that shown in Eq. (18):

$$
I(t) \cdot\left(E M F(t)+I(t) \cdot R_{\text {int }}\right)=\left|P_{\text {set }}(t)\right|
$$

$\circ$ If demanded power exceeds the power when charged at maximum allowed charging current $\left(\left|P_{\text {set }}(t)\right| \geq I_{C, \text { Max }} \cdot\left(E M F(t)+I_{C, \text { Max }} \cdot R_{\text {int }}\right)\right.$, charge the battery using the maximum allowed charging current, as shown in Eq.(21):

$$
\begin{aligned}
& I(t)=-I_{C, \operatorname{Max}} \\
& V_{C}(t)=E M F(t)+I_{C, \text { Max }} \cdot R_{\text {int }}
\end{aligned}
$$

\section{Discharging Mode:}

- Battery electromotive force is defined by Eq. (22):

$$
E M F(t)=E_{0, D}-K_{D} \frac{Q_{\max }}{Q(t)}+A_{D} e^{-B_{D}\left(Q_{\max }-Q(t)\right)}
$$

- If battery electromotive force is lower than the discharge cur-off voltage $\left(E M F(t)<E M F_{M i n}\right)$, do not discharge the battery:

$$
\begin{aligned}
& V_{C}(t)=0 \\
& I(t)=0
\end{aligned}
$$

- If demanded power exceeds the maximum deliverable power $\left(P_{s e t}(t) \geq \frac{E M F(t)^{2}}{4 * R_{\text {int }}}\right)$, regulate the battery current for maximum power delivery while keeping the current below the maximum allowed discharging current $\left(I_{D, \operatorname{Max}}\right)$ :

$$
\begin{aligned}
& V_{C}(t)=0 \\
& I(t)=\min \left(I_{D, \text { Max }}, \frac{E M F(t)}{2 * R_{\text {int }}}\right)
\end{aligned}
$$


$\circ$ If demanded power is below the maximum deliverable power $\left(P_{s e t}(t)<\frac{E M F(t)^{2}}{4 * R_{\text {int }}}\right)$, solve for the discharging current from quadratic Eq. (25). The result is reported in Eq.(26).

$$
\begin{aligned}
& \left(E M F(t)-I(t) \cdot R_{\text {int }}\right) \cdot I(t)=P_{\text {set }}(t) \\
& V_{C}(t)=0 \\
& I(t)=\frac{E M F(t)-\sqrt{E M F(t)^{2}-4 \cdot R_{\text {int }} \cdot\left|P_{\text {Set }}(t)\right|}}{2 \cdot R_{\text {int }}}
\end{aligned}
$$

\section{SIMULATION RESULTS}

In this Section, the results of the simulations are reported. To demonstrate the model capability to avoid the constraint violations discussed in Section 3, a wide range of parameters and input conditions was investigated.

\subsection{Charging mode, over-voltage protection}

In this Section, the features of over-voltage protection (Eq.(6)) and over-power protection (Eq.(8)) are demonstrated. In the performed simulations, the battery has an initial SOC value of $1.5 \%$, and a step-shaped demanded power $\left(P_{\text {set }}(t)\right)$ transitioning from 0 to $-3.0 \mathrm{~W}$ at $t=3000 \mathrm{~s}$ was imposed, as shown in Figure $5-1$.
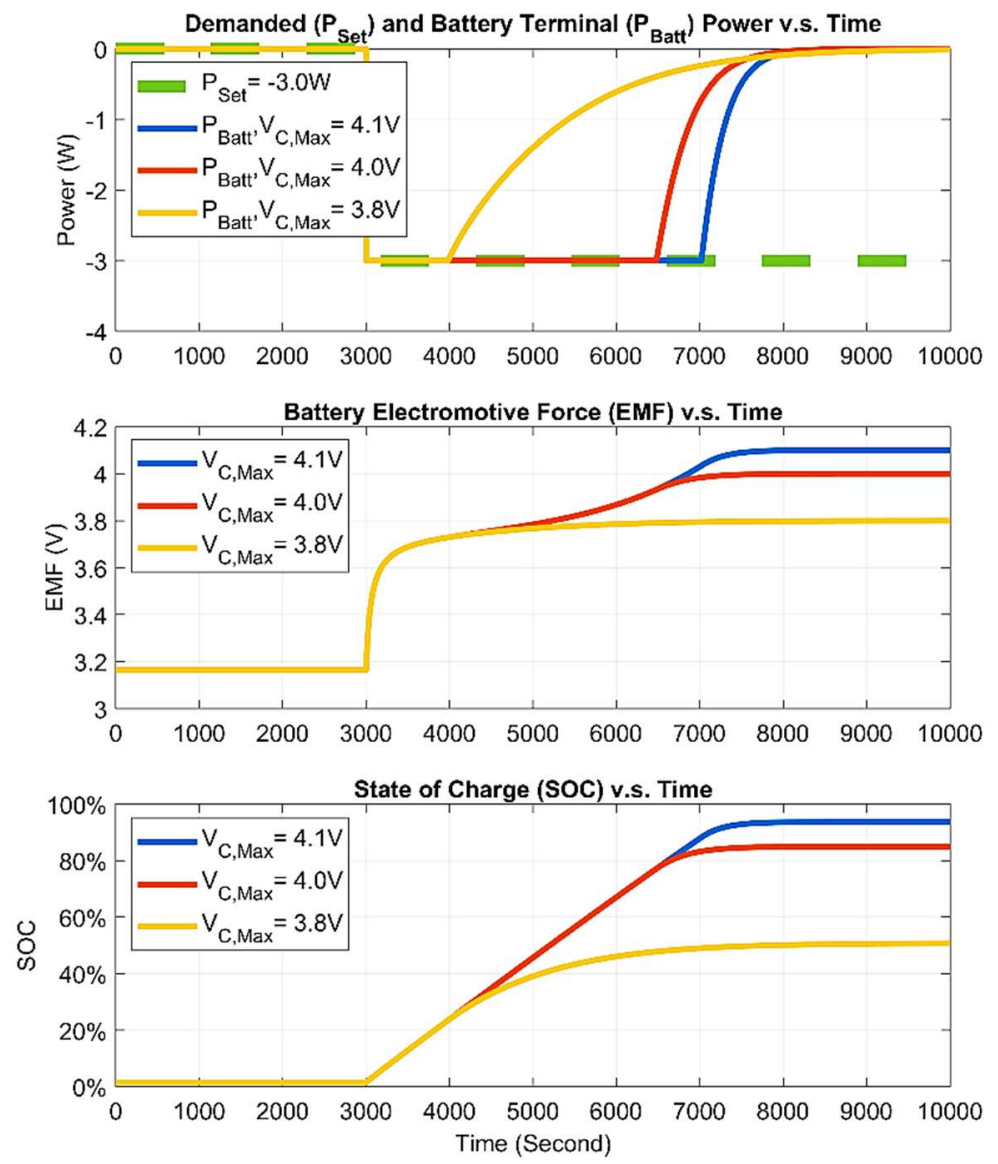

Figure 5-1. Power, EMF and SOC traces for over-voltage and over-power protection demonstration. 
All the design parameters are assigned with their default value in Table 4-1, except for that the maximum allowed charging voltage $\left(V_{C, \text { Max }}\right)$ are assigned with $4.1 \mathrm{~V}, 4.0 \mathrm{~V}$ and $3.8 \mathrm{~V}$ in the three simulations, respectively. The feature of over-voltage protection is shown in the central and bottom plot of Figure 5-1. The $E M F(t)$ and $S O C(t)$ trajectories start ramping up when the charging begins at $t=3000 \mathrm{~s}$. The slope of the $S O C$ ramp, or the battery charging current, gradually decreases as the $E M F$ rises and approaches the $V_{C, \text { Max }}$ value. The charging process interrupts when $E M F$ reaches the $V_{C, \text { Max }}$ value, as shown by the final horizontal lines in the central plot of Figure 5-1. The feature of over-power protection is shown in the top plot of Figure 5-1. The battery terminal power $P_{B a t t}(t)$ traces overlap with the demanded power $\left(P_{\text {set }}(t)\right)$ trace at the beginning of charging, and $\left|P_{B a t t}(t)\right|$ gradually decreases as the $E M F$ rises and approaches the $V_{C, \text { Max }}$ value. The $\left|P_{B a t t}(t)\right|$ never exceeds the $\left|P_{\text {set }}(t)\right|$ value.

\subsection{Charging mode, over-charge and over-current protection}

The features of over-charge protection (Eq.(5)) and over-current protection (Eq. (7)) are demonstrated in this section. In these simulations, the battery has an initial SOC value of $1.5 \%$. As shown in Figure 5-2 (top plot), a step-shaped demanded power $\left(P_{\text {set }}(t)\right)$ transitioning at $t=3000 \mathrm{~s}$ was fed to the battery model, whose value starts at zero and ends with $-4.0 \mathrm{~W},-2.5 \mathrm{~W}$ and $-1.0 \mathrm{~W}$ in the three simulations, respectively.
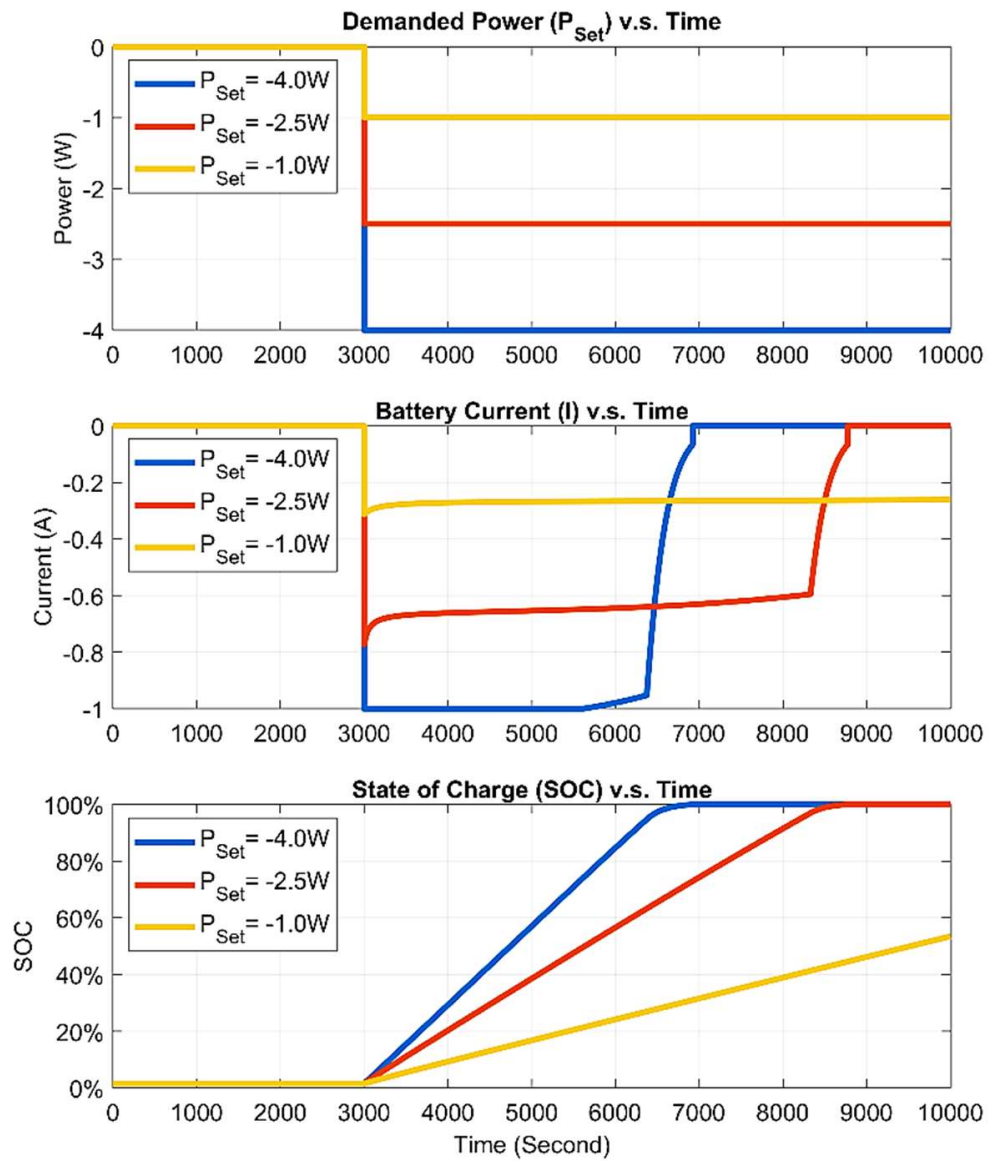

Figure 5-2. Power, current and SOC trajectories for over-charge and over-current protection demonstration. 
The feature of over-charge protection is shown in the bottom plot of Figure 5-2. The $\operatorname{SOC}(t)$ traces start to ramp up when the charging begins at $t=3000 \mathrm{~s}$. The trajectory corresponding to $-4.0 \mathrm{~W}$ and $-2.5 \mathrm{~W}$ demanded power ceased increasing when their values reached $100 \%$ before the end of simulations. The trajectory corresponding to $-1.0 \mathrm{~W}$ demanded power continues increasing till the end of simulation since its value is below $100 \%$. The feature of over-current protection is shown in the central plot of Figure 5-2. The three $I(t)$ trajectories have step-shape response when the charging begins at $t=3000 \mathrm{~s}$. The trace corresponding to $-4.0 \mathrm{~W}$ demanded power should have reached a higher value of charge current to meet the power demand, but due to the $1.0 \mathrm{~A}$ limit on the maximum allowed charging current $\left(I_{C, \text { Max }}\right)$, the charging current did not violate such constraint.

\subsection{Discharging mode, over-discharge and over-current protection}

The features of over-discharge protection (Eq. (9)) and over-current protection (Eq. (13)) are demonstrated in this section. In these simulations, the battery has an initial SOC value of $100 \%$. As shown in Figure 5-3 (top plot), a step-shaped demanded power $\left(P_{\text {set }}(t)\right)$ transitioning at $t=3000 \mathrm{~s}$ was fed to the battery model, whose value starts at zero and ends with $+5.0 \mathrm{~W},+3.0 \mathrm{~W}$ and $+1.0 \mathrm{~W}$ in the three simulations, respectively.
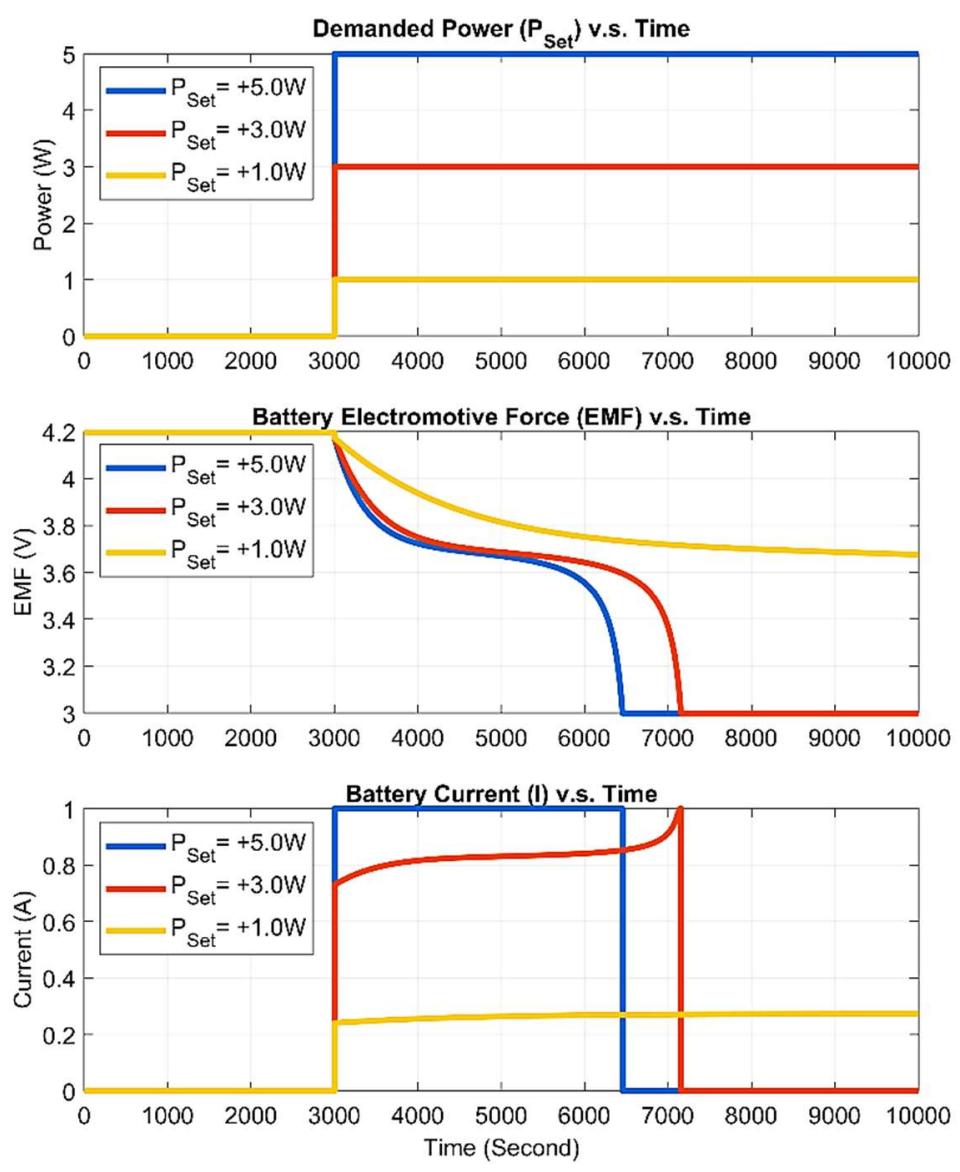

Figure 5-3. Power, EMF and current traces for over-charge and over-current protection demonstration. 
The feature of over-discharge protection is shown in the central plot of Figure 5-3. The curve corresponding to $\operatorname{EMF}(t)$ starts decreasing when the discharging begins at $t=3000 \mathrm{~s}$. The trajectories corresponding to $+5.0 \mathrm{~W}$ and $+3.0 \mathrm{~W}$ demanded power stopped decreasing when their values reached $3.0 \mathrm{~V}$, which is the battery discharge cut-off voltage $\left(E M F_{M i n}\right)$, however the trace corresponding to $+1.0 \mathrm{~W}$ demanded power continues decreasing till the end of simulation since its value is above $E M F_{M i n}$.

The feature of over-current protection is shown in the bottom plot of Figure 5-3. The three $I(t)$ traces have step-shape response when the charging begins at $t=3000 \mathrm{~s}$. The trace corresponding to $+5.0 \mathrm{~W}$ demanded power should have reached a higher value of discharge current to meet the power demand, but due to the 1.0A limit on the maximum allowed discharging current $\left(I_{D, \text { Max }}\right)$, the charging current didn't exceed such constraint. The same phenomenon is observed in the battery current trace corresponding to the $+2.5 \mathrm{~W}$ demanded power, whose value gradually increases to meet the demanded power as the EMF decreases, but its value reaches the maximum value at $I_{D, \text { Max }}$ before voltage cut-off.

\subsection{Discharging mode, over-power protection}

The feature of over-power protection (Eq.(14)) is demonstrated in this section. In this simulation, the battery has an initial SOC value of $100 \%$, and a step-shaped demanded power $\left(P_{\text {set }}(t)\right)$ transitioning from 0 to $+40.0 \mathrm{~W}$ at $t=500 \mathrm{~s}$ was fed to the battery model, as shown in Figure 5-4. All the design parameters are assigned with their default value in Table 4-1, except for that the maximum allowed discharging current $\left(I_{D, \text { Max }}\right)$, are assigned with $30.0 \mathrm{~A}$ in this simulation, as shown in the bottom plot of Figure 5-4.
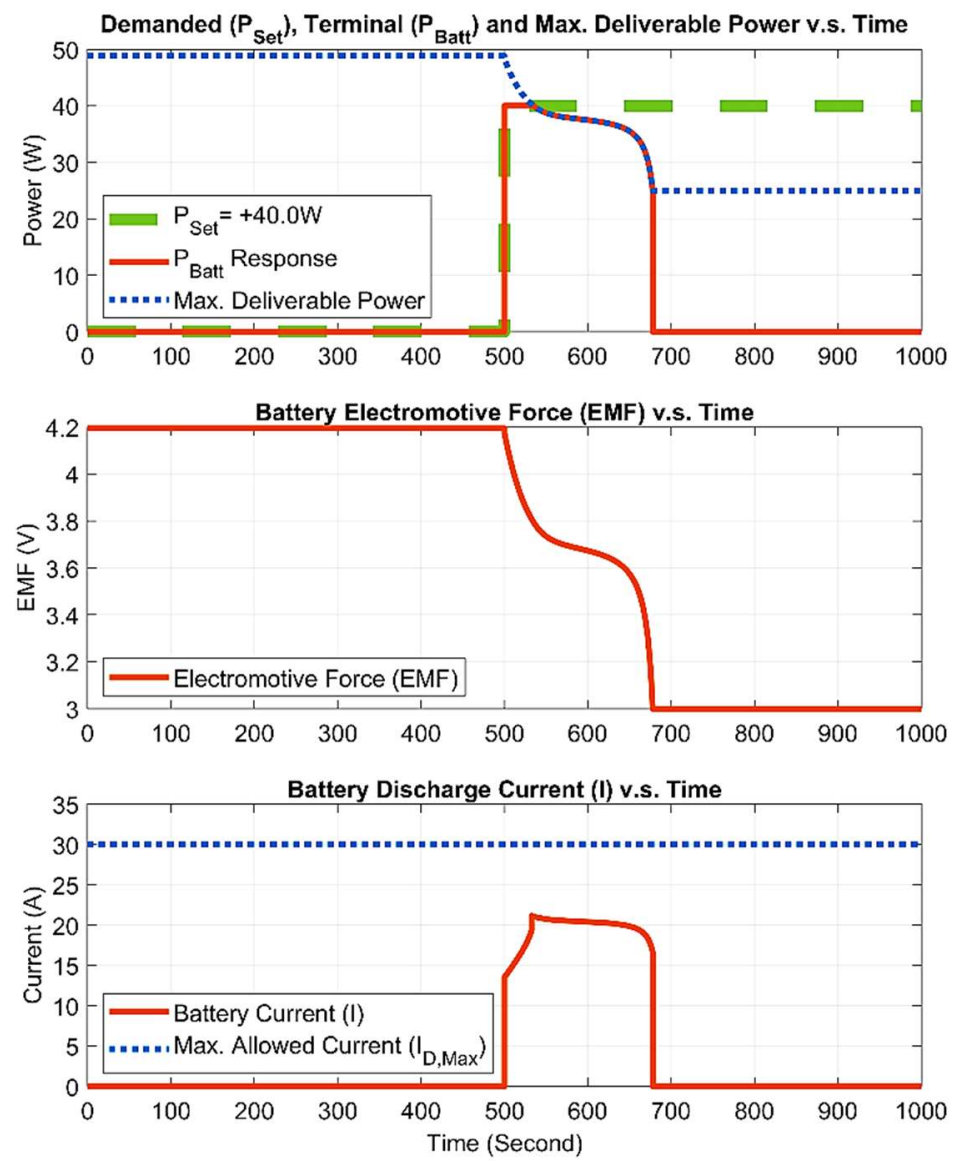

Figure 5-4. Power, EMF and current traces for over-power protection demonstration. 
The feature of over-power protection is shown in the top and central plot of Figure 5-4. When the discharging begins at $t=500 \mathrm{~s}$, the battery has an initial EMF of $4.2 \mathrm{~V}$, which made it capable of delivering $49.0 \mathrm{~W}$ power to the load (Eq.(12)). Since the demanded power is $+40.0 \mathrm{~W}$ at this moment, the battery current is adjusted to meet the demand according to Eq. (14). As the EMF gradually decreases during discharging, the maximum deliverable power becomes lower than the $+40.0 \mathrm{~W}$ demanded power since $t=536 \mathrm{~s}$, and the battery current is adjusted according to Eq. (12) to ensure the maximum power delivery.

\section{HERON MODELING OF DEGRADATION PHENOMENA AFFECTING ELECTRO- CHEMICAL BATTERIES}

The understanding of degradation mechanisms in Li-ion batteries is essential for maximum service life of these components [15]. At the same time, given the purposes of the CTD-IES project, the progressive fade of the capacity (Section 6.1), the reduction of the round-trip efficiency (Section 6.2), and the limits on the number of charging/discharging cycles (Section 6.3) are aspects that need to be accurately characterized and taken into account in techno-economic analysis. Currently, the models implemented in HERON of energy-storing components do not account for the possibility that the installed capacity might progressively reduce throughout the service lifetime, and do not keep track of the history of charge/discharge cycles associated with their amplitude and impact over the operation and maintenance (O\&M) costs. Modeling of these performance degradation phenomena becomes crucial when predictions on long-time horizons (capacity expansion) are made.

Degradation of Li-ion batteries, basically, starts from the moment they are first used. This is as a result of the fundamental chemistry of the battery, which gives rise to unavoidable chemical reactions that occur inside the battery during operation. In a healthy battery, ions can freely flow between a cathode and an anode, i.e., charging a battery forces ions from the cathode to the anode, and discharging a battery reverses the flow. Theoretically, this mechanism should work forever, but cycling, elevated temperature and aging decrease the performance over time. The manufacturers are striving to improve Li-ion battery lifetimes in many ways. Examples of battery enhancement techniques include the structural reinforcement of electrode materials through cationic doping or additive introduction into the electrolyte.

\subsection{Capacity fade}

Rechargeable Li-ion batteries gradually lose their capacity to hold a charge. The currently adopted metrics to represent the battery performance is the state of health $(\mathrm{SOH})$, i.e., the ratio between the residual capacity and the nominal one. State-of-the-art Li-ion batteries lose about $20 \%$ of their capacity after 1000 charge cycles [15].

This aging process is irreversible and it is mainly due to (1) a loss of active electrode material (if the cathode material becomes unstable at high potentials, it can no longer store lithium), to (2) a loss of Li ions in the electrode active materials, and to (3) a loss of electrolyte [1]. Recent studies have shown that the loss of active electrode material is actually low compared to the loss of active lithium (loss of storage content). Active Li can get lost due to formation of a solid electrolyte interface (SEI) on the surface of the graphite that constitutes the anode. SEI formation is inevitable. Liquid electrolytes decompose at the graphite surface to form SEI, which protects the electrolyte against further decomposition. Li is consumed in these decomposition reactions [15]. SEI is not only built at the beginning of life (BOL) of the battery. During operation, both the electrode and the anode particles suffer from volume changes and mechanical stresses. In particular, the volume change for graphite can be up to $10 \%$, and it eventually causes the SEI to break. 
A new SEI will then be built on top of fresh graphite surface, and the lithium consumptions will continue because of these changes of the particle surface, and the cell progressively loses capacity. While capacity losses are relevant over the course of the battery life, it is negligible for each cycle [1].

Several factors degrade the SOH of a battery. The usage conditions when recharging the battery (e.g., frequent rapid charging) can accelerate the damage. The environment within which the battery operates (factors such as temperature, duty cycle and pack construction) will also have a profound effect on how quickly the battery ages. In [3], commercial Li-ion batteries based on LFP $\left(\mathrm{LiFePO}_{4}\right), \mathrm{NCA}\left(\mathrm{LiNi}_{\mathrm{x}} \mathrm{Co}_{\mathrm{y}} \mathrm{Al}_{1}\right.$ $\left.{ }_{x-y} \mathrm{O}_{2}\right)$, and $\mathrm{NMC}\left(\mathrm{LiNi}_{\mathrm{x}} \mathrm{Mn}_{\mathrm{y}} \mathrm{Co}_{1-\mathrm{x}-\mathrm{y}} \mathrm{O}_{2}\right)$ chemistries were cycled with varying temperature, depth of discharge, and discharge rate. Results show that the capacity fade rate increases with increased temperature for LFP cells but decreases for NMC cells. The NCA cells did not exhibit a strong temperature dependence in the examined range. Different temperature dependences suggest different dominant degradation mechanisms. Besides, high discharge rates accelerate the capacity fade process by inducing stress on the electrodes from rapid volume change that increases stress and microcracks. Newly-formed cracks enable further reaction between the electrolyte and $\mathrm{Li}$, leading to more SEI formation, loss of Li inventory, and capacity fade. Independently on the testing conditions, all cells reach $80 \%$ capacity between 1000 and 4000 cycles. Besides, all cells exhibited primarily linear degradation behavior, with slightly more rapid fade at the beginning and end of life.

With regard to accounting these dependencies in HERON models, this level of complexity can hardly be accomplished. To this aim, it is reasonable to assume a single temperature operating conditions and to adopt a conservative approach on the cycle counting, i.e., every charge/discharge cycle counts as an equivalent full cycle (EFC).

\subsection{Round-trip efficiency loss}

As important as the current value of the capacity, the efficiency is a key performance indicator for Liion batteries. The round-trip efficiency (RTE) is the amount of energy that the battery can deliver relative to the amount of energy injected into it during the immediately preceding charge, i.e., it is the ratio of the available energy during discharge to the energy required to charge a battery. A Li-ion battery loses about $5 \%$ of energy round trip, which means that it has a $95 \%$ round trip efficiency, compared to lead acid batteries which lose $20-25 \%$ of energy round trip [16]. RTE depends on the cycling conditions, including temperature, SOC, and rest time. Besides, RTE varies at different charging and discharging power. However, for economic evaluations, a single RTE value is often assumed [3].

During battery service lifetime, RTE suffers degradation phenomena as well. The progressive reduction of this variable is due to the combined effect of two loss mechanisms, i.e., (1) the conversion losses and (2) the auxiliary system power consumption. The former losses are related to the conversion and storage of energy in the power electronics and battery respectively; the latter losses are related to the additionally necessary power for the operation of the system, namely thermal management as well as the control and monitoring components [17][18]. According to [3], the RTE can vary up to $10 \%$ among fresh cells depending on the cycling conditions and can decrease over $5 \%$ as a cell ages. With respect to the capacity fade, the RTE loss is a less penalizing issue. As for HERON implementation, it is sufficient that RTE is yearly updated by reducing its value to a given quantity that corresponds to the average value of the charge/discharge cycles occurred during the year. 


\subsection{Limit on the number of charge/discharge cycles}

Given the loss of capacity and the efficiency degradation related to each cycle, the service lifetime for a Li-ion battery is usually expressed in terms of calendar life and cycle life [19]. The cycle life is the number of complete cycles a battery can be charged and discharged before its capacity degrades to $80 \%$ of its initial capacity. A complete cycle refers to the complete drainage and recharge of a battery, i.e., draining a battery to $0 \%$ and recharging it to $100 \%$ is equal to one battery charge cycle. A charge cycle can also be completed by using $50 \%$ of the battery, recharging it to $100 \%$ and then repeating this procedure. Similar to mechanical devices that wears out faster with heavy use, the depth of discharge (DoD) determines the cycle count of the battery, i.e., the smaller the discharge (low DoD), the longer the battery will last. Charge/discharge cycles at given DoD is a commonly adopted measure of service lifetime of batteries. Traditionally, a maximum number of cycles is imposed for each year of operation. As for HERON implementation, two modeling approaches are proposed:

(1) Currently, HERON cannot track the number of charge/discharge cycles at given DoD. If this capability is implemented in the code, when the imposed limit on the number of cycles is reached, the service lifetime will be considered over, and the battery unit will need to be replaced. Besides, the impact on the O\&M costs will need to be accounted for.

(2) If the capacity loss corresponding to each charge/discharge cycle at given DoD was available, the service lifetime of the unit could be retrieved by imposing a minimum value to the residual capacity. This approach would be more accurate, and it would allow pushing the performance that can be obtained. In specification sheets, manufacturers usually adopt $80 \%$ to indicate end of life, whereas cells are used beyond $80 \%$ capacity in grid applications [3].

\section{HERON ECONOMICAL VALUES}

In order to model the economics of a Li-ion battery system in HERON, several key economical values are required, as listed in Table 7-1. Among these values, the capital and O\&M cost are used to characterize the cost during its construction, operation, and maintenance; the RTE and its degradation factor are used to capture the cost of dissipated energy due to limited efficiency; the limits on number of cycles and service lifetime serve as a criteria to determine the end of battery service life and trigger the unit replacement. It is worth it noting that the impact on capacity of temperature, depth of discharge, and discharge rate are chemistry-specific as reported in [3], i.e., dependences in one chemistry should not be broadly extrapolated to all $\mathrm{Li}$-ion batteries. In Table 7-1, the set of costs and parameters of a reference $\mathrm{Li}$-ion battery unit are provided based on a weighted average of commercially deployed Li-ion battery systems [1].

Table 7-1. Summary of costs and parameters for a reference Li-ion battery unit.

\begin{tabular}{lc}
\hline \multicolumn{1}{c}{ Parameter } & Value \\
\hline Capital Cost - Energy Capacity, $(\$ / \mathrm{kWh})$ & $223-323$ \\
Power Conversion System, $(\$ / \mathrm{kW})$ & $230-470$ \\
O\&M fixed, $(\$ / \mathrm{kW}-\mathrm{yr})$ & 10.0 \\
O\&M variable, $\left(10^{-2} \$ / \mathrm{kWh}\right)$ & 0.03 \\
Round-trip efficiency, $(-)$ & 0.86 \\
\hline
\end{tabular}




\begin{tabular}{lc}
\hline Annual RTE degradation factor, (-) & $0.50 \%$ \\
Number of cycles at $80 \%$ Depth of Discharge, (-) & 3500 \\
Service lifetime, $(\mathrm{yr})$ & 10
\end{tabular}

\section{CONCLUSION}

The main focus of this work was the development of a Dymola model of an electrochemical energy storage unit. As representative technology, Li-ion batteries were selected. Starting from the previously attempts [7], a model of a reference unit complying with the requirements of the ecosystem plug-and-play library was realized in Dymola simulation environment. Based on a modified version of the Shepherd model, the developed component allows simulating the electric dynamic response of a Li-ion battery ensuing from an imposed charging/discharging power profile. The corresponding physical limitations related to over-power scenarios, and the impact of the residual state of charge are accounted for. Once tested during some operational transients, the model was uploaded to the repository.

In the second part of the report, a literature review about the major degradation processes affecting Liion batteries is provided. Given the purposes of the CTD-IES project, the progressive shrinking of the installed capacity, the reduction of the round-trip efficiency, and the limits on the number of charging/discharging cycles are aspects that need to be taken into account in techno-economic analysis. For each one of these phenomena, a brief description is given, and some figures to be implemented in HERON optimization algorithm are reported. Finally, a data set of costs and parameters for a reference Li-ion battery unit was provided. 


\section{REFERENCE}

[1] K Mongird et al., "Energy Storage Technology and Cost Characterization Report", PNNL-28866 (2019).

[2] P.T. Moseley, J. Garche, "Electrochemical energy storage for renewable sources and grid balancing", Elsevier (2015).

[3] Y. Preger et al., "Degradation of Commercial Lithium-Ion Cells as a Function of Chemistry and Cycling Conditions", Journal of The Electrochemical Society, 167 (2020).

[4] A.A. Pesaran, G.-H. Kim, M. Keyser, "Integration Issues of Cells into Battery Packs for Plug-In and Hybrid Electric Vehicles”, EVS-24 International Battery, Hybrid and Fuel Cell Electric Vehicle Symposium, Stavanger (Norway), May 13-16 (2009).

[5] A.S. Subburaj, S.B. Bayne, M.G. Giesselmann, M.A. Harral, "Analysis of Equivalent Circuit of the Utility Scale Battery for Wind Integration”, IEEE Transactions on Industry Applications, 52(1), 25-33 (2016).

[6] Center for the Commercialization of Electric Technologies (CCET), "Technology solutions for wind integration in ERCOT”, Final Technical Report (2015).

[7] R. Ponciroli, Y. Tang, T. Hua, R.B. Vilim, "Development of Models for Equipment Components in Hybrid Energy Systems", Argonne National Laboratory, ANL/NE-16/25 (2016).

[8] O. Tremblay, L.A. Dessaint, A.I. Dekkichem, "A Generic Battery Model for the Dynamic Simulation of Hybrid Electric Vehicles", Proceedings of the Vehicle Power and Propulsion Conference, IEEE, 284-289 (2007).

[9] Modelica, http://www.modelica.org, 2011.

[10] P. Fritzson, "Principles of Object-Oriented Modeling and Simulation with Modelica 3.3", Second Edition, Wiley-IEEE Press (2015).

[11] Dynasim, Dymola Version 2015. http://www.dynasim.se (2015).

[12] F. Casella, A. Leva, "Modeling of thermo-hydraulic power generation processes using Modelica", Mathematical and Computer Modelling Dynamic System, 12(1), 19-33 (2006).

[13] Data Power Technology Limited, Polymer Li-ion Rechargeable Battery Product Specifications, E-SPE-031001, https://cdn.sparkfun.com/assets/5/6/e/1/5/SPE-DTP603450-1000mah-3.7V-En-1.0V.pdf (Last accessed on Aug 30, 2021).

[14] A. Epiney, R. Kinoshita, J. S. Kim, C. Rabiti, M. Greenwood, "Software development infrastructure for the HYBRID modeling and simulation project", Idaho National Laboratory, INL/EXT-16-40004 (2016).

[15] S. Gantenbein, M. Schönleber, M. Weiss, E. Ivers-Tiffee, "Capacity fade in lithium-ion batteries and cyclic aging over various state-of-charge ranges”, Sustainability, 11(23), 6697 (2019).

[16] M. Safoutin, J. Cherry, J. McDonald, S. Lee, "Effect of Current and SOC on Round-Trip Energy Efficiency of a Lithium-Iron Phosphate (LiFePO4) Battery Pack", SAE 2015 World Congress \& Exhibition (2015).

[17] M. Schimpe et al., "Energy efficiency evaluation of a stationary lithium-ion battery container storage system via electro-thermal modeling and detailed component analysis", Applied Energy, 210, 211-229 (2018).

[18] M.R. Schimpe, "System Simulation of Utility-Scale Lithium-Ion Battery Energy Storage Systems", Doctoral Dissertation, Technische Universität München (2018).

[19] S. Xiong, "A study of the factors that affect lithium-ion battery degradation", M.Sc. dissertation, University of Missouri-Columbia (2019). 


\section{APPENDIX A}

model BatteryLevel 2

"Level 2 Li-ion Battery with charge curve and internal resistance"

// Some parameters were found at:

// 1. https://cdn. sparkfun.com/assets/5/6/e/1/5/SPE-DTP603450-1000mah-3.7V-En-

1.OV.pdf

// 2. Tremblay, Olivier, Louis-A. Dessaint, and Abdel-Illah Dekkiche. "A generic

// battery model for the dynamic simulation of hybrid electric vehicles." In

// 2007 IEEE Vehicle Power and Propulsion Conference, pp. 284-289. Ieee, 2007. import Modelica.SIunits.Conversions.NonSIunits.*;

import Modelica.SIunits.Conversions. *;

Modelica.Blocks.Interfaces.Realinput psetPoint (unit="w")

"Demanded power output [W]" annotation (Placement (transformation (extent $=\{\{-120$, $-20\},\{-80,20\}\}), i c o n T r a n s f o r m a t i o n(\operatorname{extent}=\{\{-120,-20\},\{-80,20\}\})))$;

NHES.Electrical.Interfaces.ElectricalPowerPort_b powerConnection

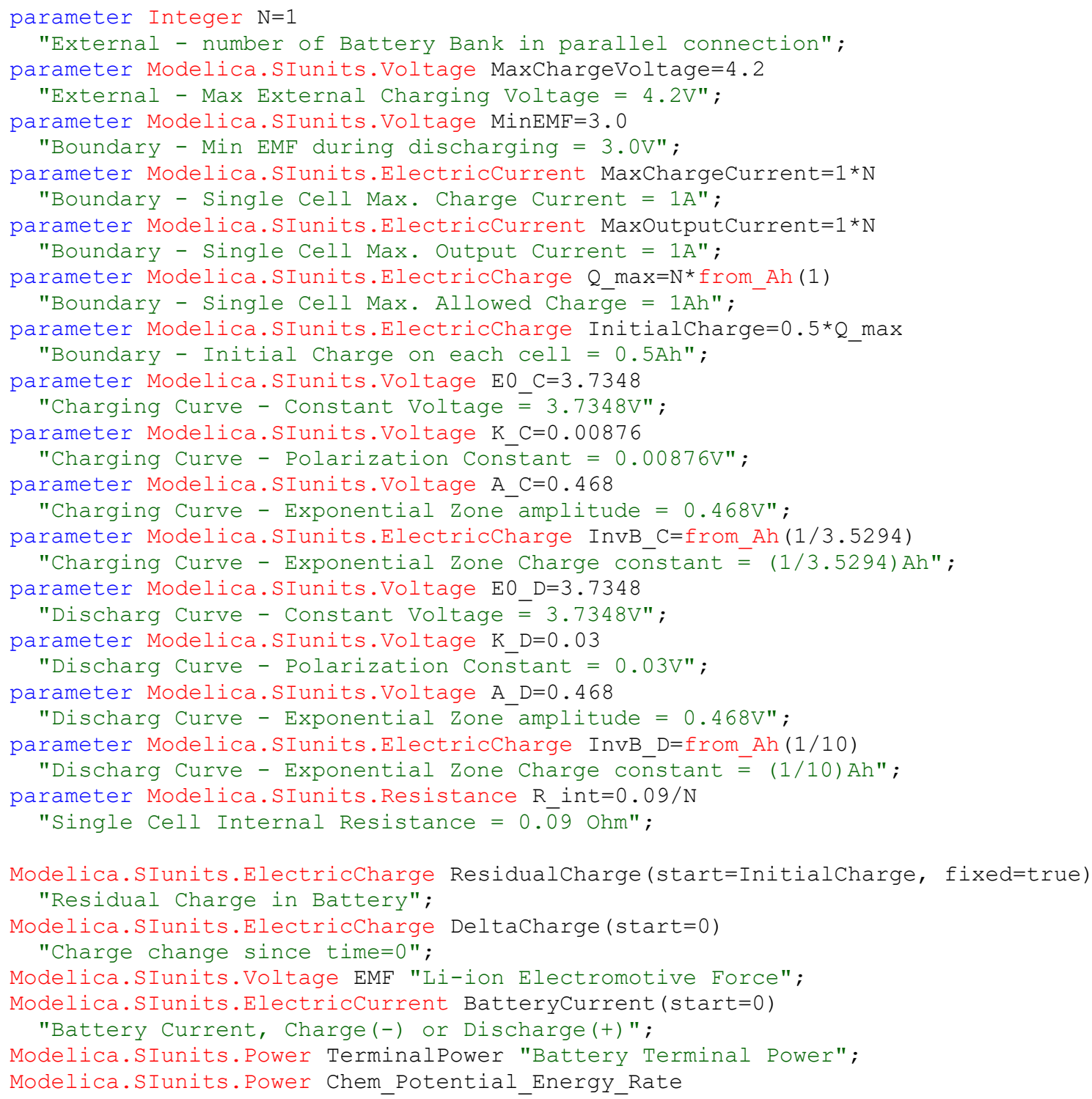


"Battery Chemical Potential Energy Drop Rate Charging(-)/Discharge(+)" ; Modelica.SIunits.Frequency f "Electrical frequency";

Modelica.SIunits.Voltage ChargeVoltage "Adjusted External Charging Voltage"; Real StateofCharge "Q/QMax";

equation

assert (MaxChargeVoltage > 0, "External Charging Voltage should be positive value!"); assert(R_int > 0, "Internal Resistance R_int should be positive value!");

der(DeltaCharge) = -BatteryCurrent;

// dQ/dt=-I, for the battery charging level

StateofCharge = ResidualCharge/Q_max;

if psetPoint $<=0$ then

// Charging curve of Li-ion battery, EMF as a function of residualcharge

$\mathrm{EMF}=\mathrm{EO} \_\mathrm{C}-\mathrm{K} \_\mathrm{C}^{\star} \mathrm{Q} \_\mathrm{max} /$ ResidualCharge $+\mathrm{A}_{-} \mathrm{C}^{\star} \exp (-(\mathrm{Q}$ max - ResidualCharge $) / \mathrm{InvB} \mathrm{C}) ;$ else

// Discharging curve of Li-ion battery, EMF as a function of residualcharge

$\mathrm{EMF}=\mathrm{E} 0 \_\mathrm{D}-\mathrm{K}_{-} \mathrm{D}^{*} Q_{-} \max /$ ResidualCharge $+\mathrm{A}_{-} \mathrm{D}^{*} \exp \left(-\left(Q_{-} \max -\operatorname{ResidualCharge}\right) /\right.$ InvB_D$) ;$ end if;

if psetPoint $<0$ then

//Charge mode, psetPoint == negative, Batterycurrent $==$ negative

if Residualcharge < Q max then

// When the battery is not full yet

if $\mathrm{EMF}<$ MaxChargeVoltage then

// MaxChargeVoltage is higher than EMF

if (MaxChargeVoltage-EMF)/R int < MaxChargeCurrent then

// If Current doesn't overiload when Charge under MaxChargeVoltage,

// try to charge at MaxChargeVoltage.

if abs(pSetPoint) < MaxChargeVoltage* (MaxChargeVoltage-EMF)/R int then

// If power exceeds demand when charging at MaxChargeVoltage,

// solve the 2nd order polynomial $V_{C} *(V C-E M F) / R i n t=a b s$ (pSetPoint)

else

ChargeVoltage $=\left(\mathrm{EMF}+\operatorname{sqrt}\left(\mathrm{EMF}^{\wedge} 2+4 * \mathrm{R}\right.\right.$ int*abs $($ petPoint $\left.\left.)\right)\right) / 2$;

// If power within demand when charging at MaxChargeVoltage,

// impose the MaxChargeVoltage

ChargeVoltage = MaxChargeVoltage; end if;

else

// If Current overloads when Charge under MaxChargeVoltage,

// reduce the ChargeVoltage to match psetPoint

if abs (psetPoint) < MaxChargeCurrent* (EMF+R_int*MaxChargeCurrent) then

// If demanded charging power is less than the Max allowed terminal

// power (under MaxChargeCurrent), solve the 2nd order polynomial

ChargeVoltage $=\left(\mathrm{EMF}+\operatorname{sqrt}\left(\mathrm{EMF}^{\wedge} 2+4{ }^{\star} \mathrm{R} \_\right.\right.$int*abs (pSetPoint $\left.\left.)\right)\right) / 2$;

else

// If demanded charging power exceeds the Max allowed terminal

// power (under MaxChargeCurrent), impose the MaxChargeCurrent

ChargeVoltage $=\mathrm{EMF}+\mathrm{R}$ int*MaxChargeCurrent;

end if;

end if: else

BatteryCurrent $=-($ ChargeVoltage $-\mathrm{EMF}) / \mathrm{R}$ int;

// MaxChargeVoltage is lower than EMF, no charging

ChargeVoltage $=0.0$;

Batterycurrent $=0.0$; end if;

else

// When battery is full, no charging

ChargeVoltage $=0.0$;

BatteryCurrent $=0.0$; 


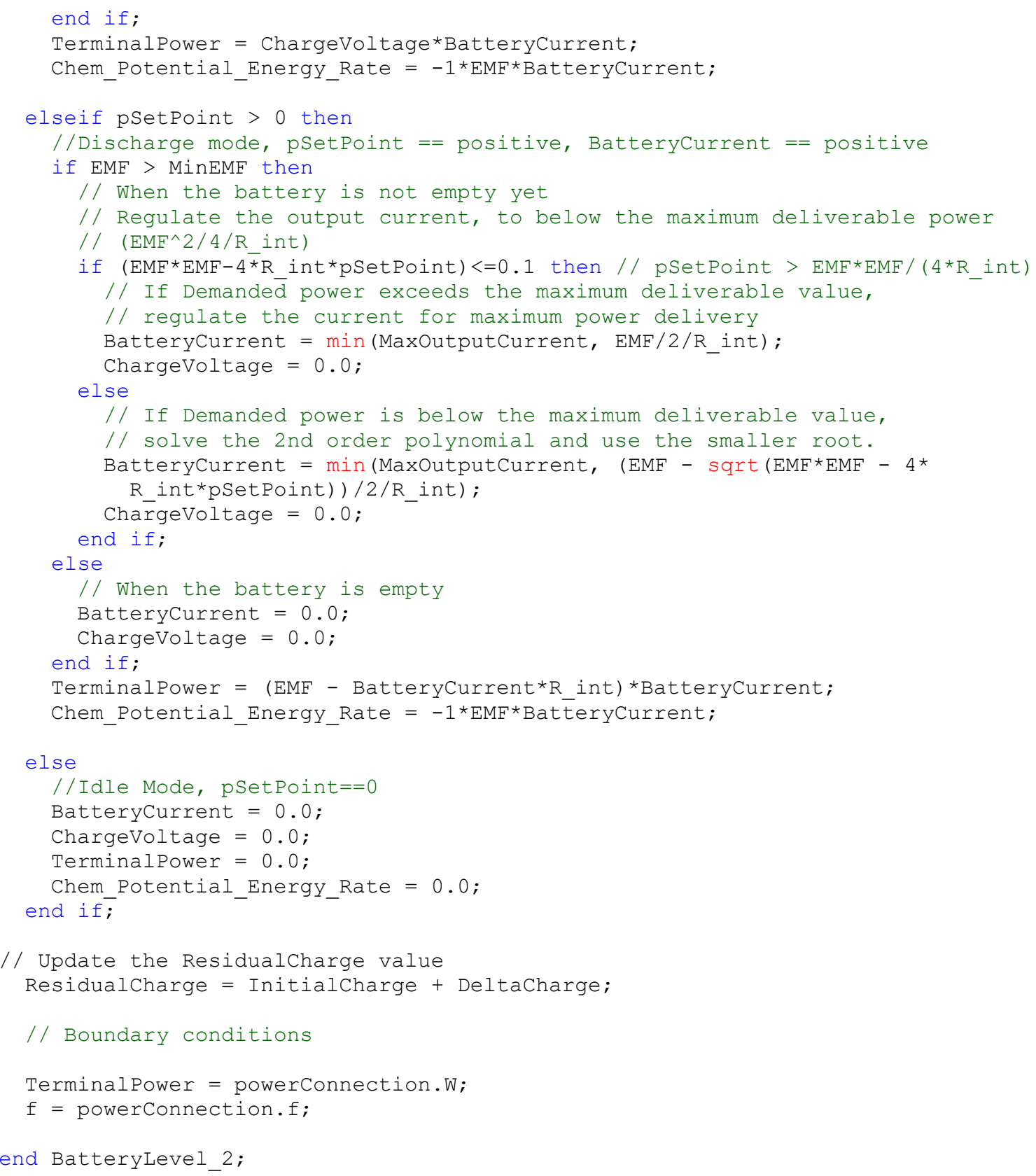




\section{Argonne}

\section{Nuclear Science and Engineering (NSE) Division}

Argonne National Laboratory

9700 South Cass Avenue, Bldg. 208

Argonne, IL 60439

www.anl.gov

Argonne National Laboratory is a U.S. Department of Energy laboratory managed by UChicago Argonne, LLC 